\title{
Development of Preparation Method for Microencapsulating Uycalyptus Oil Containing Fine Aqueous Droplets by Use of Interfacial Condensation Reaction between Hydroxy Propyl Methyl Cellulose and Tannic Acid
}

\author{
Hiroyuki Sato, Yoshinari Taguchi, Masato Tanaka* \\ Graduate School of Science and Technology, Niigata University, Niigata, Japan \\ Email: ${ }^{*}$ tanaka@eng.niigata-u.ac.jp
}

Received 25 June 2014; revised 14 July 2014; accepted 10 August 2014

Copyright (C) 2014 by authors and Scientific Research Publishing Inc.

This work is licensed under the Creative Commons Attribution International License (CC BY). http://creativecommons.org/licenses/by/4.0/

(c) (i) Open Access

\begin{abstract}
It was tried to develop the preparation method for microencapsulating the uycalyptus oil containing fine aqueous droplets by using the interfacial condensation reaction between hydroxyl propyl methyl cellulose and tannic acid. Uycalyptus oil containing fine aqueous droplets was dispersed in the continuous water phase to form the (W/0)/W emulsion. Tannic acid and hydroxyl propyl methyl cellulose were dissolved in the inner aqueous droplets and in the outer continuous water phase, respectively. Tannic acid transferred through the oil phase from the inner water droplets to the interface between the oil phase and the continuous water phase and then, reacted with hydroxyl propyl methyl cellulose. In the experiment, the concentrations of hydroxyl propyl methyl cellulose and tannic acid were mainly changed stepwise. The uycalyptus oil containing the fine water droplets could be microencapsulated satisfactorily. It was found that the microcapsules were composed of the gelated hydroxyl propyl methyl cellulose film as the shell, the fine aqueous droplets as the first core and the oil droplet as the second core.
\end{abstract}

\section{Keywords}

Microcapsule, Uycalyptus Oil, Multiple Emulsion, Interfacial Condensation Reaction, Hydroxyl Propyl Methyl Cellulose, Tannic Acid

\footnotetext{
${ }^{*}$ Corresponding author.

How to cite this paper: Sato, H., et al. (2014) Development of Preparation Method for Microencapsulating Uycalyptus Oil Containing Fine Aqueous Droplets by Use of Interfacial Condensation Reaction between Hydroxy Propyl Methyl Cellulose and Tannic Acid. Journal of Cosmetics, Dermatological Sciences and Applications, 4, 219-227. http://dx.doi.org/10.4236/jcdsa.2014.44030
} 


\section{Introduction}

Many kinds of microcapsules have been developed and applied to the various fields such as cosmetics, paintings, catalyst, food industry, medicine, agriculture, and so on [1]-[3].

The purposes of microencapsulation are to optionally release the core material, to protect the core materials from environment, to modify the surface of core material, to mask the taste of core material and so on. These functions of microcapsules are strongly dependent on the physical properties of shell and core materials, the structure, size and morphology of microcapsules. Accordingly, in order to prepare the microcapsules with the desired functions, it is necessary to develop the preparation method which is suitable to the physical properties of the core and shell materials used.

Recently, many studies about the microencapsulation of essential oils have been reported [4]-[10]. These microcapsules have been applied to the textiles, fragrance, aromatherapy, insect repelling, stress reducing, antibiosis and so on.

Uycalyptus oil is known to have many physiological activities such as anti-aging effect, anti-inflammation effect, sterilization effect, anti-uilus and so on. If the microcapsules containing the uycalyptus oil could be prepared and the oil could be optionally released, the uycalyptus oil will be utilized extremely easily in the more fields. Furthermore, it will be expected that the microcapsules containing the uycalyptus oil have to develop the new fields and the applicable fields of oil will be dramatically increased. Until now, many kinds of oil species have been microencapsulated with the chemical methods such as interfacial gelling reaction method [11]-[13], the in-situ polymerization [14] [15], the interfacial polycondensation reaction [16] [17] and the physicochemical methods such as the coacervation method [18] [19], the spray-dried method [20]-[22], and the melting dispersion-cooling method [23]. In these preparation methods, a few harmful chemical species have been used and the complicated processes have been applied. However, if we are going to apply the microcapsules to the cosmetics, the food and the drug, the microcapsules have to be prepared with the materials suitable to the living body and the edible materials. Accordingly, it is necessary to newly develop the preparation method by using the designnated materials with the simple process. The purposes of this paper are to develop the microencapsulation procedure with the interfacial condensation reaction between hydroxyl propyl methyl cellulose and tannic acid, to investigate whether the microcapsules of uycalyptus oil containing the fine water droplets can be prepared or not, to characterize the microcapsules and to discuss the microencapsulation mechanism on the basis of the results obtained.

\section{Experimental}

\subsection{Materials}

Materials used to develop the preparation method for microencapsulating the uycalyptus oil containing the fine water droplets are as follows:

The first core material was Uycalyptus oil (UO) (Wako Junyaku Co., Ltd.). Span 80 (Wako Junyaku Co., Ltd.) and Soybean Lecithin (Wako Junyaku Co., Ltd.) were used as the oil soluble surfactant. Hydroxy propyl methyl cellulose (HPMC) (50SH-50: Shinetsu Chemical Ind Co., Ltd.) and Tannic acid (TA) were used as the reactants to form the microcapsule shell. These chemical species were used as received.

\subsection{Pre-Microencapsulation}

In order to investigate whether the microcapsules can be prepared by the microencapsulation mechanism presented in this study or not, the pre-microencapsulation experiment was tried as follows.

Figure 1 shows the schematic diagram of pre-microencapsulation procedure. Namely, the HPMC aqueous solution and the UO were poured into the beaker as shown in Figure 1. The UO and the HPMC aqueous solution were separated to form the upper oil phase and the lower aqueous phase, respectively. Then, the TA aqueous solution was dropped into the oil phase through the nozzle by the syringe pump. If TA could transfer through the oil phase and react with HPMC on the interface between the oil phase and the HPMC aqueous solution, the gelated HPMC film should be formed on the interface. As a result, the TA aqueous droplet may be maintained on the formed film for a while.

According to this microcapsule shell formation mechanism, the pre-microencapsulation experiment was performed by changing the concentrations of HPMC and TA. 


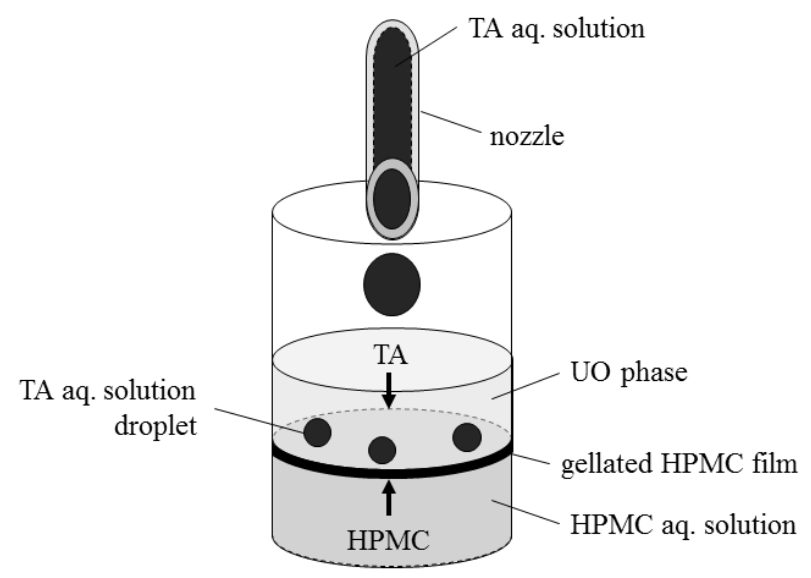

Figure 1. Pre-microencapsulation procedure.

\subsection{Preparation of Microcapsules}

Figure 2 shows the schematic diagram of experimental apparatus used to prepare the microcapsules. The reactor was the separable flask with the effective volume of $500 \mathrm{~cm}^{3}$. Four baffles made of aluminium plate were set on the wall of reactor. The six bladed disc turbine impeller with the diameter of $5 \mathrm{~cm}$ was used to stir the reaction mixture. The reactor was set in the thermos tatted water bath to keep temperature of reaction mixture constant. Figure 3 shows the flow chart for microencapsulating the UO containing the fine water droplets by using the interfacial condensation reaction between HPMC and TA. The aqueous solution dissolving TA as a gelation agent was dispersed into the UO dissolving Soybean Lecithin (SL) of an oil soluble surfactant to form the (W/O) emulsion.

Then, the (W/O) emulsion was dispersed into the continuous water phase dissolving HPMC to form the $(\mathrm{W} / \mathrm{O}) / \mathrm{W}$ emulsion. The operation stated above was performed at room temperature.

After formation of the (W/O)/W emulsion, temperature of the (W/O)/W emulsion was raised to $30^{\circ} \mathrm{C}$ to perform the condensation reaction between TA and HPMC. When the reaction was continued for $1 \mathrm{~h}$, it was investigated whether the microcapsules of UO containing the fine water droplets could be prepared or not.

The formation of microcapsules was confirmed by observing the stability of the (W/O)/W emulsion after the microencapsulation process and by optical microscope. If the microcapsules were prepared well, the photographs of them were taken. Contrary to this, if the microcapsules were not prepared well, the emulsion should be broken rapidly.

In the fundamental experiment stated above, the concentrations of HPMC and TA were mainly changed. The experimental conditions in this experiment were shown in Table 1.

\subsection{Characterization}

\subsubsection{Mean Diameter of Microcapsules}

The microcapsules were observed by optical microscope and the photographs of them were taken. The diameter distributions and mean diameters of microcapsules were measured directly from these photographs.

\subsubsection{Stability of Emulsion and Microcapsules}

In order to investigate whether the microcapsules can be prepared or not, the (W/O)/W emulsion after microencapsulation process was set for $10 \mathrm{~min}$. If the microcapsules could not be prepared well, the (W/O) droplets should be rapidly broken. The shape and inner structure of microcapsules were observed by taking the optical microscopic photographs.

\subsubsection{Observation of Formation of Microcapsule Shell}

The formation of microcapsule shell was observed to find the optimum concentrations of HPMC and TA.

Namely, the UO and the HPMC aqueous solution were poured into the beaker. The UO floated on the HPMC aqueous solution and the interface between the oil phase and the HPMC aqueous solution was formed as shown 


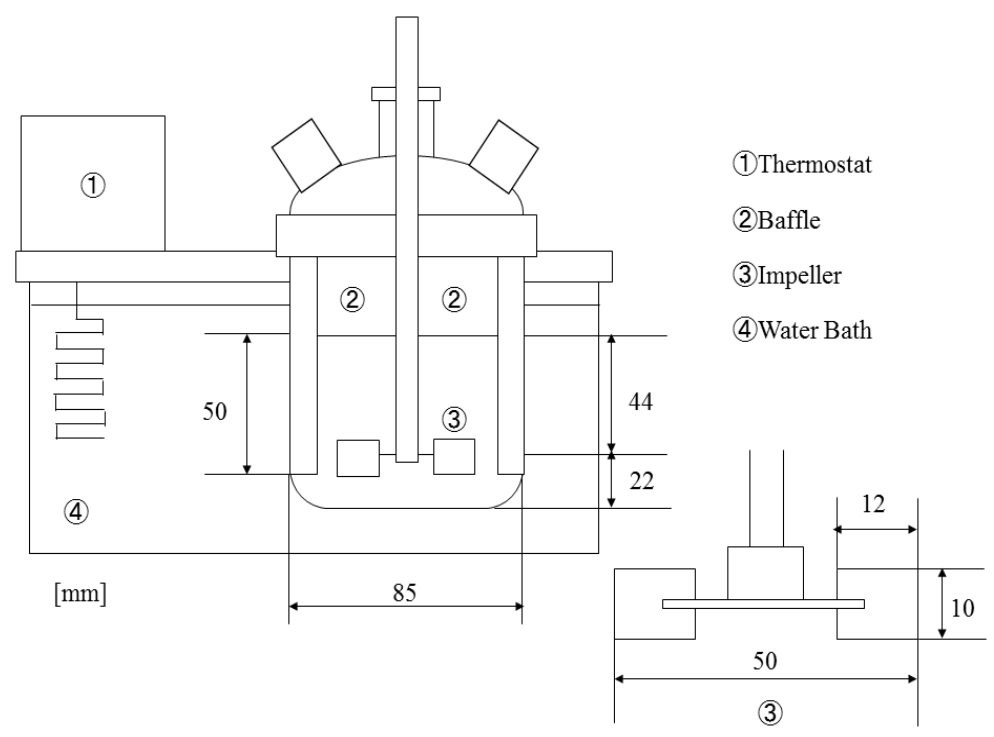

Figure 2. Schematic diagram of experimental apparatus.

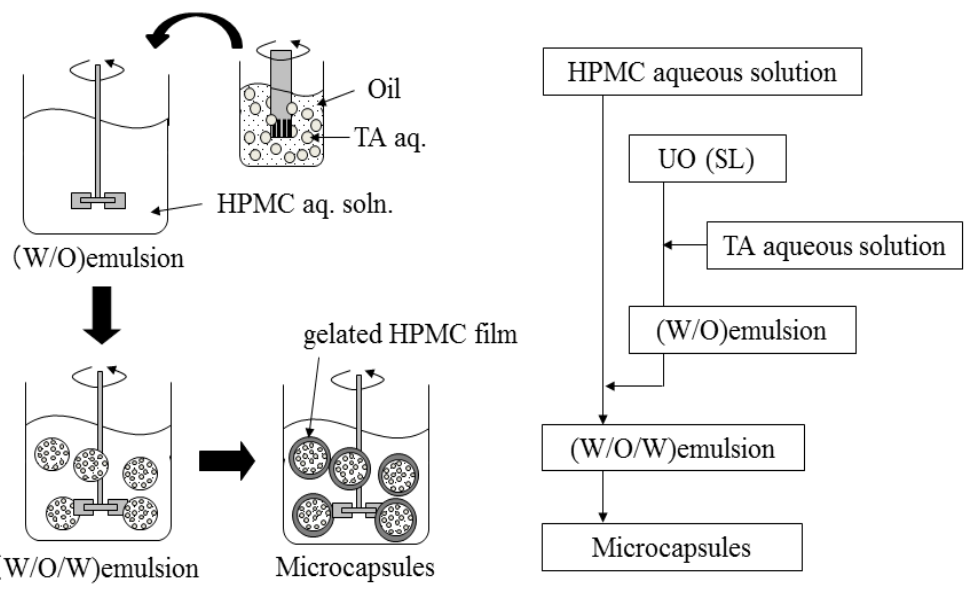

Figure 3. Flow chart for preparing microcapsules.

Table 1. Experimental conditions.

- $\quad$ HPMC aq. soln. concent. of HPMC [C $\left.\mathrm{C}_{\mathrm{HPMC}}\right]$

- Uycalyptus oil concent. of Lecithin $\left[\mathrm{C}_{\mathrm{TA}}\right]$

- TA aq. soln. concent. of TA

- Revolution speed for formation of (W/O) emulsion Stirring time

- Revolution speed for (W/O)/W emulsion [Nr] Stirring time Reaction Temp. Reaction time
$270 \mathrm{ml}$

$0.05-0.2 \mathrm{wt} \%-\mathrm{H}_{2} \mathrm{O}$

$27 \mathrm{ml}$

0.1 wt\%-Uycalyptus oil

$3 \mathrm{ml}$

0 - $0.1 \mathrm{~mol}$

$1000 \mathrm{rpm}$

$3 \mathrm{~min}$

$200 \mathrm{rpm}$

$5 \mathrm{~min}$

$30^{\circ} \mathrm{C}$

$1 \mathrm{~h}$

in Figure 1. The time elapsing from arrival of TA aqueous droplet at the interface to disappearance of droplet was measured. The concentrations of HPMC and TA required to form the gelated HPMC film could be estimated by observing the stability of a TA aqueous droplet on the interface. 


\section{Results and Discussion}

\subsection{Confirmation of Shell Formation and Microencapsulation Mechanism}

Figure 4 shows the photographs of the TA aqueous droplet and the interface on which the gelated HPMC film was formed according to the concentrations of HPMC and TA. When the concentrations of HPMC and TA were low $\left(\mathrm{C}_{\mathrm{HPMC}}=0.05 \mathrm{wt} \%, \mathrm{C}_{\mathrm{TA}}=0.01 \mathrm{~mol}\right)$, the TA aqueous droplet was kept on the interface as shown in Figure 4(a), but dissolved into the HPMC aqueous solution in a few min. The short life of TA aqueous droplet on the interface may be due to the formation of thinner film. On the other hand, when the concentrations of HPMC and TA were higher $\left(\mathrm{C}_{\mathrm{HPMC}}=0.2 \mathrm{wt} \%, \mathrm{C}_{\mathrm{TA}}=0.06 \mathrm{~mol}\right)$, the $\mathrm{TA}$ aqueous droplet was kept on the interface for ca. 10 min as shown in Figure 4(b) due to the thicker film formation.

Figure 5 shows the measured results of the time elapsing from arrival of a TA aqueous droplet at the interface to disappearance. From these results, it is found that the film was not formed at $\mathrm{C}_{\mathrm{TA}}=0$ in spite of elapsing of ca. $30 \mathrm{~s}$ and the gelated film was formed above the concentrations of $\mathrm{C}_{\mathrm{HPMC}}=0.05 \mathrm{wt} \%$ and $\mathrm{C}_{\mathrm{TA}}=0.01 \mathrm{~mol}$. Here, ca. 8 min at $C_{\text {HPMC }}=0.05 \mathrm{wt} \%$, and ca. 10 min at $C_{\text {HPMC }}>0.1 \mathrm{wt} \%$ don't mean that the TA aqueous droplet disappeared at these elapsing times, but mean that the measurement of elapsing time was finished at these times.

From these results, as the gelated HPMC film was found to be formed on the interface between the UO and the HPMC aqueous solution above $\mathrm{C}_{\mathrm{HPMC}}=0.05 \mathrm{wt} \%$ and $\mathrm{C}_{\mathrm{TA}}=0.01 \mathrm{~mol}$. Taking these results into consideration, the formation mechanism of film may be stated as shown in Figure 6. TA should transfer from the TA aqueous droplet to the interface through the UO and react with HPMC on the interface to form the gelated HPMC film. If the concentrations of HPMC and TA are lower, the thinner shell film should be formed. Contrary to this, if the concentrations of HPMC and TA are higher, the thicker and stronger shell film should be formed.

Furthermore, it was investigated whether the microcapsules could be prepared or not by the preparation method presented in this study. Namely, the stability of the (W/O)/W emulsion was observed with and without the microencapsulation process.

Figure 7 shows the photographs of the (W/O)/W emulsion just after the microencapsulation process (a) and after $10 \mathrm{~min}(\mathrm{~b})$. The (W/O)/W emulsion without the microencapsulation process was separated rapidly into the oil phase and the water phase, but the observation result is not shown. Contrary to this, the (W/O)/W emulsion with the microencapsulation process, namely the $(\mathrm{W} / \mathrm{O})$ droplets microencapsulated floated on the water phase and was kept to stably disperse as shown in Figure 7(b). From these results, the UO droplets containing the fine water droplets were estimated to be microencapsulated well by the gelated HPMC shell.

\subsection{Observation of Microcapsules}

Figure 8 shows the optical microscopic photographs of microcapsules prepared by changing the concentration of HPMC at $\mathrm{C}_{\mathrm{TA}}=0.06 \mathrm{~mol}$. From these photographs, the following interesting results are obtained. The microcapsules could be prepared according to the formation mechanism presented in this study. The mean diameters of microcapsules changed from $780 \mu \mathrm{m}$ to $1330 \mu \mathrm{m}$ by changing the concentration of HPMC as shown in Figure 8. The fine water droplets were microencapsulated well, but become larger due to coalescence between the fine water droplets. In order to stably disperse the fine water droplets in the oil droplet and to utilize as the first core material, it must be necessary to select the optimum oil soluble surfactant species and the concentrations of them. The microcapsules become irregular with the concentration of HPMC. This result is considered to be due to the fact that the oil droplets containing the fine water droplets are hard to break by the stronger shell formed with the higher concentration and become irregular. These microcapsules could be stably dispersed in the continuous water phase under stirring of revolution speeds from $200 \mathrm{rpm}$ to $500 \mathrm{rpm}$ with the six bladed disc turbine impeller of $5 \mathrm{~cm}$ diameter.

\subsection{Formation Mechanism of Microcapsules}

From the results obtained above, the formation mechanism of microcapsules may be presented as shown in Figure 9. TA dissolved in the inner water droplets should transfer to the interface through the UO phase, react with HPMC on the interface and form the gelated HPMC film as the microcapsule shell.

In the case of the lower concentration of HPMC or TA, as the weak shell is formed, the (W/O) emulsion may be broken. As a result, the microcapsules cannot be prepared. Contrary to this, in the case of the higher concentration of HPMC and TA, as the stronger shell is formed, the microcapsules can be prepared well. The fine inner 
(a)

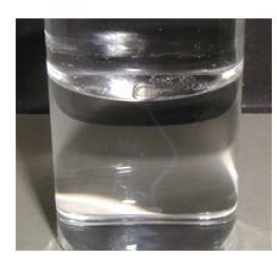

$\mathrm{C}_{\mathrm{HPMC}}=0.05 \mathrm{wt} \%$

$\mathrm{C}_{\mathrm{TA}}=0.01 \mathrm{~mol}$
TA aq. droplet
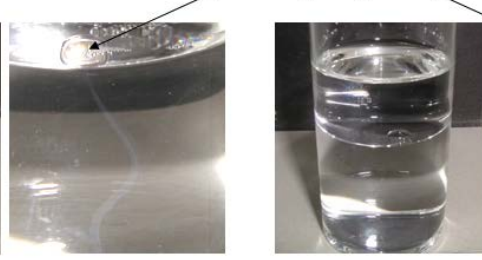

$\mathrm{C}_{\mathrm{HPMC}}=0.2 \mathrm{wt} \%$

$\mathrm{C}_{\mathrm{TA}}=0.06 \mathrm{~mol}$ (b)

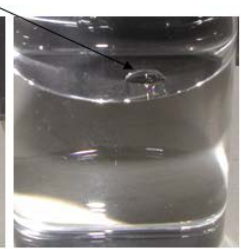

Figure 4. Confirmation of microcapsule shell formation.

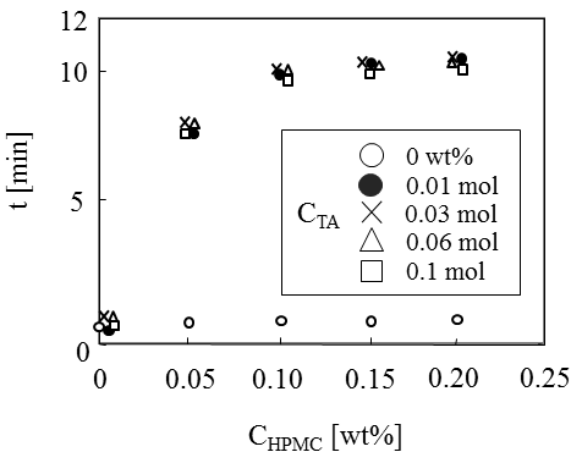

Figure 5. Effect of concentrations of HPMC and TA on film formations.

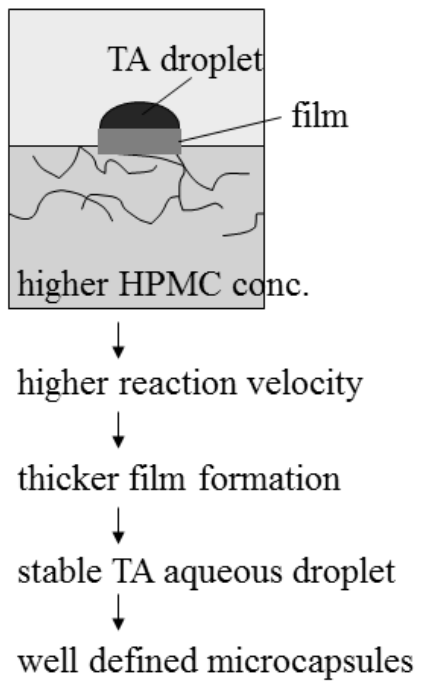

Figure 6. Formation mechanism of gelated HPMC film.

water droplets may coalesce each other to form the larger water droplets. If the fine water droplets could be dispersed stably, TA may transfer rapidly due to the larger interface area between the UO phase and the inner water phase. As a result, the shell may be formed rapidly and the microcapsules may be prepared more satisfactory. As many kinds of chemical species can be dissolved in the fine inner water droplets as the first core material and in the oil phase as the second core material at the same time, the microcapsules will be given the many kinds of functions. Namely, the microcapsules with the multiple functions can be prepared by using the microencapsulation method developed in this study.

However, it has to be investigated whether the microcapsules with the other oil species can be prepared by the microencapsulation mechanism presented here or not. Because, as it is necessary for TA to transfer through the 


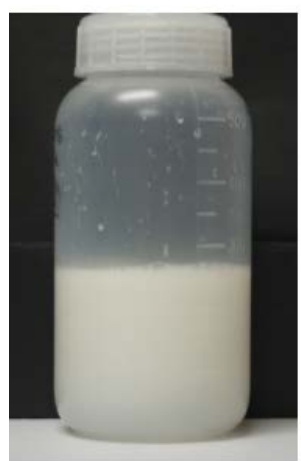

(a) just after

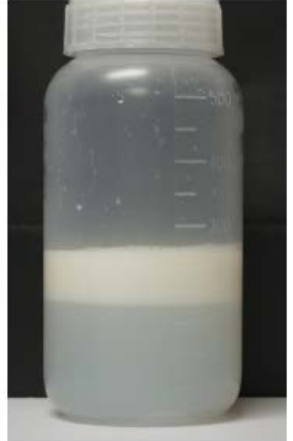

(b) after 10min

Figure 7. Photographs of (W/O)/W emulsion just after microencapsulation and after elepsing $10 \mathrm{~min}$.

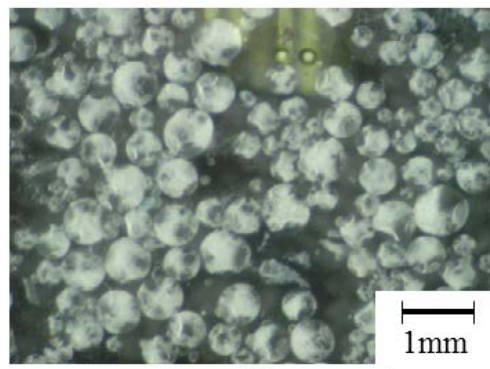

$0.05 w \mathrm{t} \%\left(\mathrm{~d}_{\mathrm{p}}=780 \mu \mathrm{m}\right)$

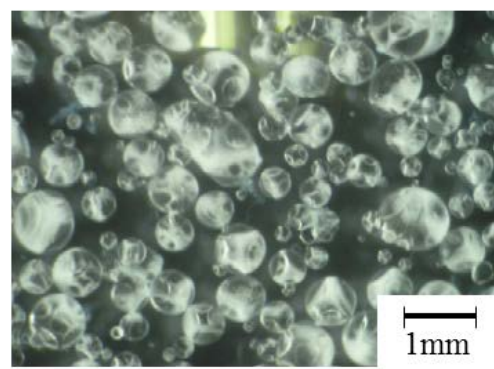

$0.15 \mathrm{wt} \%\left(\mathrm{~d}_{\mathrm{p}}=1100 \mu \mathrm{m}\right)$

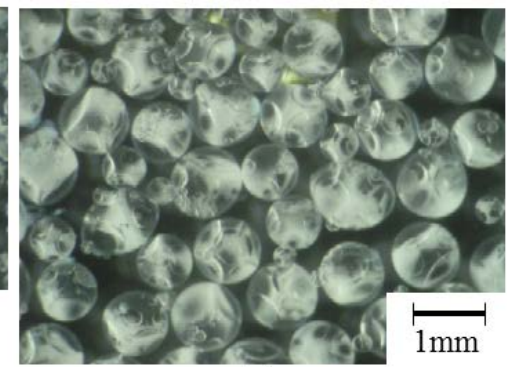

$0.1 w t \%\left(d_{p}=910 \mu m\right)$

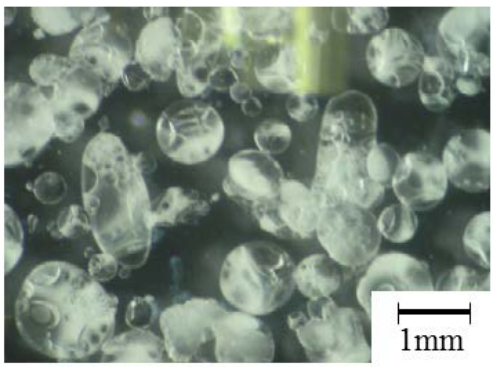

$0.2 \mathrm{wt} \%\left(\mathrm{~d}_{\mathrm{p}}=1330 \mu \mathrm{m}\right)$

$\mathrm{C}_{\mathrm{TA}}=0.06 \mathrm{~mol}, \mathrm{Nr}=200 \mathrm{rpm}$

Figure 8. Photographs of microcapsules prepared by changing concentrations of HPMC.

oil phase, the fundamental experiments with regard to mass transfer of TA in the other oil species have to be performed.

\section{Conclusions}

It was tried to microencapsulate the uycalyptus oil droplets containing the fine water droplets according to the microencapsulation mechanism presented. The following results were obtained.

1) TA transferred from the water droplets to the interface between the uycalyptus oil and the HPMC aqueous solution through the uycalyptus oil and reacted with HPMC.

2) The preparation method for microencapsulating the uycalyptus oil containing the fine water droplets could be developed.

3) There were the critical concentrations $\left(\mathrm{C}_{\mathrm{HPMC}}=0.05 \mathrm{wt} \%, \mathrm{C}_{\mathrm{TA}}=0.01 \mathrm{~mol}\right)$ for $\mathrm{HPMC}$ and TA required to prepare the sound microcapsules.

4) The microcapsules become irregular with the concentrations of HPMC. 


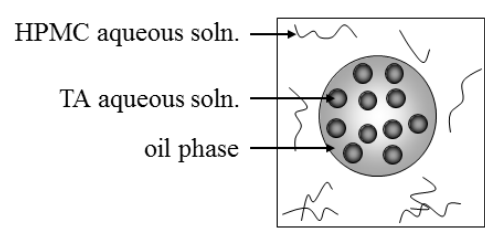

(W/O)/W emulsion

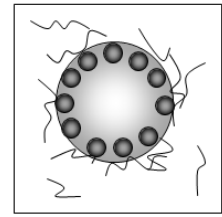

Reaction of TA with HPMC on interface

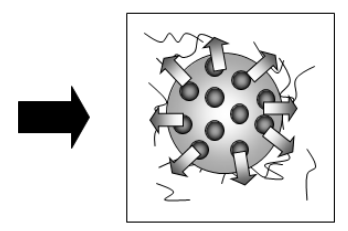

transfer of TA to interface gelated HPMC film

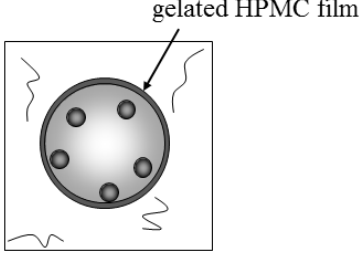

shell formation

Figure 9. Microencapsulation mechanism.

5) The fine water droplets coalesced each other to form the larger water droplet.

6) As the microencapsulation method developed is the simple process with nontoxic materials, it may be expected that this method is going to be applied in many kinds of fields.

\section{References}

[1] Kondo, T. (1967) Saishin Maikurokapseruka Gijutsu (Microencapsulation Technique). TES, Tokyo.

[2] Tanaka, M. (2008) Key Point of Preparation of Nano/Microcapsules. Techno System Publishing Co. Ltd., Tokyo.

[3] Koishi, M., Eto, K. and Higure, H. (2005) (Preparation + Utilization) Microcapsules. Kogyo Chosakai, Tokyo.

[4] Wang, J.M., Zheng, W., Song, Q.W., Zhu, H. and Zhou, Y. (2009) Preparation and Characterization of Natural Fragrant Microcapsules. Journal of Fiber Bioengineering and Informatics, 1, 293-300. http://dx.doi.org/10.3993/jfbi03200907

[5] Lee, H., Jeong, C., Ghafoor, K., Cho, S. and Park, J. (2011) Oral Delivery of Insulin Using Chitosan Capsules CrossLinked with Phytic Acid. Bio-Medical Materials and Engineering, 21, 25-36.

[6] Suthaphot, N., Chulakup, S., Chonsakorn, S. and Mongkholrattanasit, R. (2012) Application of Aroma Therapy on Cotton Fabric by Microcapsules. International Conference: Textiles \& Fashion 2012, Bangkok, 3-4 July 2014.

[7] Satapathy, D., Biswas, D., Behera, B., Sagiri, S.S., Pal, K. and Pramanik, K. (2013) Sunflower-Oil-Based Lecithin Organogels as Matrices for Controlled Drug Delivery. Journal of Applied Polymer Science, 129, 585-594. http://dx.doi.org/10.1002/app.38498

[8] Hsieha, W.C., Changb, C.P. and Gaoc, Y.L. (2006) Controlled Release Properties of Chitosan Encapsulated Volatile Citronella Oil Microcapsules by Thermal Treatments. Colloids and Surfaces B: Biointerfaces, 53, 209-214. http://dx.doi.org/10.1016/j.colsurfb.2006.09.008

[9] Iamrungraksa, T. and Charuchinda, S. (2010) Preparation and Characteristics of Galangal Essential Oil/Alginate Microcapsules. Journal of Metals, Materials and Minerals, 20, 89-92.

[10] Soliman, E.A., El-Moghazy, A.Y., Mohy El-Din, M.S. and Massoud, M.A. (2013) Microencapsulation of Essential Oils within Alginate: Formulation and in Vitro Evaluation of Antifungal Activity. Journal of Encapsulation and Adsorption Sciences, 3, 48-55. http://dx.doi.org/10.4236/jeas.2013.31006

[11] Paques, J.P., van der Linden, E., van Rijn, C.J. and Sagis, L.M. (2014) Preparation Methods of Alginate Nanoparticles. Advances in Colloid and Interface Science, 209, 163-171. http://dx.doi.org/10.1016/j.cis.2014.03.009

[12] Belyaeva, E., Valle, D.D., Neufeld, R.J. and Poncelet, D. (2004) New Approach to the Formulation of Hydrogel Beads Byemulsi \& Cation/Thermal Gelation Using a Static Mixer. Chemical Engineering Science, 59, 2913-2920. http://dx.doi.org/10.1016/j.ces.2004.04.010

[13] Wang, A., Tao, C., Cui, Y., Duan, L., Yang, Y. and Li, J. (2009) Assembly of Environmental Sensitive Microcapsules of PNIPAAm and Alginate Acidand Their Application in Drug Release. Journal of Colloid and Interface Science, 332, 271-279. http://dx.doi.org/10.1016/j.jcis.2008.12.032

[14] Katoh, K., Yoshimura, H. and Fujita, H. (2005) Preparation of Porous Matrices of Natural Polymer Using Microcapsules. Aichiken Sangyou Gijutsu Kenkyuujo kenkyuu houkoku, 4, 200-203. 
[15] Tian, K., Xie, C. and Xia, X. (2013) Chitosan/Alginate Multilayer film for Controlled Release of IDM on Cu/LDPE Composite Intrauterine Devices. Colloids and Surfaces B: Biointerfaces, 109, 82-89. http://dx.doi.org/10.1016/j.colsurfb.2013.03.036

[16] Su, J.F., Wang, S.B., Zhang, Y.Y. and Huang, Z. (2011) Physicochemical Properties and Mechanical Characters of Methanol-Modified Melamine-Formaldehyde (MMF) Shell MicroPCMS Containing Paraffin. Colloid and Polymer Science, 289, 111-119. http://dx.doi.org/10.1007/s00396-010-2328-1

[17] Yuan, Y., Zhang, N., Tao, W., Cao, X. and He, Y. (2014) Fatty Acids as Phase Change Materials: A Review. Renewable and Sustainable Energy, 29, 482-498. http://dx.doi.org/10.1016/j.rser.2013.08.107

[18] Yang, Z., Peng, Z., Li, J., Li, S., Kong, L., Li, P. and Wang, Q. (2014) Development and Evaluation of Novel Flavour Microcapsules Containing Vanilla Oil Using Complex Coacervation Approach. Food Chemistry, 145, 272-277. http://dx.doi.org/10.1016/j.foodchem.2013.08.074

[19] Chang, C.P., Leung, T.K., Lin, S.M. and Hsu, C.C. (2006) Release Properties on Gelatin-Gum Arabic Microcapsules Containing Camphor Oil with Added Polystyrene. Colloids and Surfaces B: Biointerfaces, 50, 136-140. http://dx.doi.org/10.1016/j.colsurfb.2006.04.008

[20] Soottitantawat, A., Bigeard, F., Yoshii, H., Furuta, T., Ohkawara, M. and Linko, P. (2005) Influence of Emulsion and Powder Size on the Stability Ofencapsulated d-Limonene by Spray Drying. Innovative Food Science and Emerging Technologies, 6, 107-114. http://dx.doi.org/10.1016/j.ifset.2004.09.003

[21] Polavarapu, S., Oliver, C.M., Ajlouni, S. and Augustin, M.A. (2012) Impact of Extra Virgin Olive Oil and Ethylenediaminetetraacetic Acid (EDTA) on the Oxidative Stability of Fish Oil Emulsions and Spray-Dried Microcapsules Stabilized by Sugar Beet Pectin. Journal of Agricultural and Food Chemistry, 60, 444-450. http://dx.doi.org/10.1021/jf2034785

[22] Gharsallaoui, A., Saurel, R., Chambin, O., Cases, E., Voilley, A. and Cayot, P. (2010) Utilisation of Pectin Coating to Enhance Spray-Dry Stability of Pea Protein-Stabilised Oil-in-Water Emulsions. Food Chemistry, 122, 447-454. http://dx.doi.org/10.1016/j.foodchem.2009.04.017

[23] Taguchi, Y., Ono, F. and Tanaka, M. (2013) Preparation of Microcapsules Containing $\beta$-Carotene with Thermo Sensitive Curdlan by Utilizing Reverse Dispersion. Pharmaceutic, 5, 609-620. http://dx.doi.org/10.3390/pharmaceutics5040609 
Scientific Research Publishing (SCIRP) is one of the largest Open Access journal publishers. It is currently publishing more than 200 open access, online, peer-reviewed journals covering a wide range of academic disciplines. SCIRP serves the worldwide academic communities and contributes to the progress and application of science with its publication.

Other selected journals from SCIRP are listed as below. Submit your manuscript to us via either submit@scirp.org or Online Submission Portal.
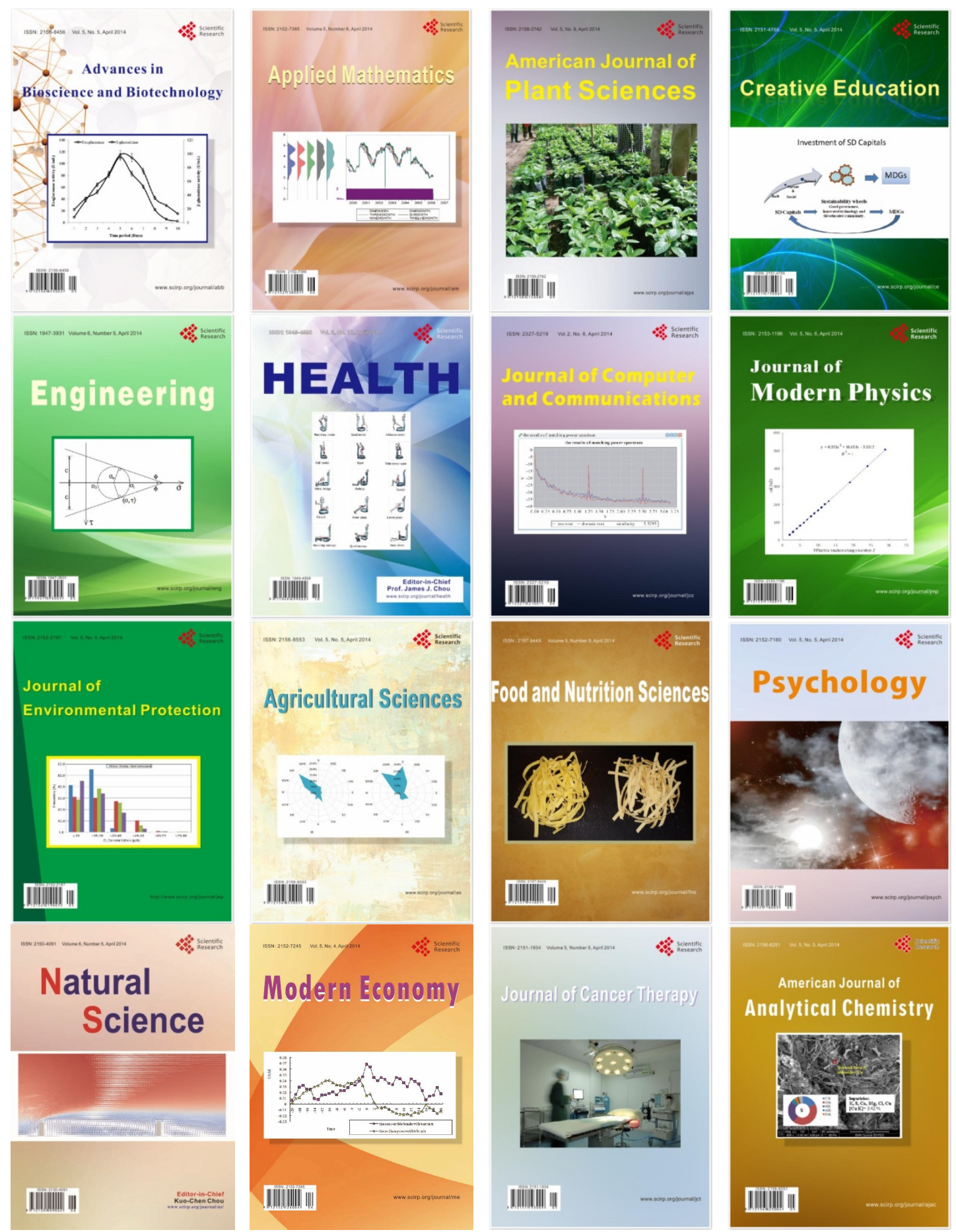